\title{
REVISÃO DOS CONHECIMENTOS SOBRE O RELEVO DO PLANALTO ATLÂNTICO BRASILEIRO: INCÓGNITAS QUE AINDA PERSISTEM
}

Quererá isto dizer, entretanto que a diferença de resistência das rochas explique tudo? E, se não for assim, poder-se-á encontrar um principio que permita discriminar os acidentes diretamente devidos a deformações recentes, dos devidos simplesmente a uma adaptação a estrutura dum embasamento antigo?

Emmanuel De Martonne - 1940

\section{Roberto José Hezer Moreira Vervloet ${ }^{1}$ Jurandyr Luciano Sanches Ross ${ }^{2}$}

Resumo: $O$ artigo procura traçar o estado atual dos conhecimentos sobre o relevo do Planalto Atlântico brasileiro, através de revisão bibliográfica sobre as pesquisas realizadas desde a década de 1930 até os dias atuais. Nesta revisão é possível observar a formação de quatro correntes de explicação sobre a gênese do relevo do Planalto Atlântico que respondeu pela formação de uma verdadeira escola de pensamento geocientífica brasileira. Em primeiro lugar há uma corrente de modelos geomorfológicos erosivos com implicações tectônicas, em segundo é possível verificar uma outra corrente com enfoque morfoclimático baseado nas mudanças climáticas do Terciário, em terceiro há uma seqüência de pesquisas que não é fundamentalmente geomorfológica, mas de enfoque predominantemente tectônico associado com elementos geomórficos, $e$, por último, há trabalhos destacando a formação por processos geoquímicos das feições geomórficas e até as superfícies aplainadas embutidas entre os grandes compartimentos de relevos regionais (Serra do Mar $e$ Mantiqueira). A conclusão é que nenhuma dessas correntes são capazes de explicar totalmente a gênese geomórfica do Planalto, permanecendo velhas incógnitas que desafiam as abordagens apresentadas, nascendo novas questões e persistindo indagações que passam de período em período e de escola em escola.

Palavras-Chave: Planalto Atlântico; Tectônica; Superfície de Aplainamento; Gênese do relevo.

\section{REVIEW OF KNOWLEDGE ABOUT THE TOPOGRAPHY OF THE BRAZILIAN ATLANTIC HIGHLANDS: UNKNOWNS THAT STILL REMAIN.}

\begin{abstract}
This paper attempts to outline the current state o knowledge on the importance of the Brazilian Atlantic Plateau, through an extensive review of the literature on studies conducted since the 1930s to the present day. In this review, it is possible to observe the development of a true school of Brazilian geoscientific thought. Firstly, there is a line of erosive geomorphological models with tectonic implications. Secondly, it is possible to find another strain with morphoclimatic approach based on Quaternary climate change. Thirdly, there is a sequence of research that is not primarily geomorphological, but whose focus is

\footnotetext{
${ }^{1}$ Geógrafo. Mestre em Geografia Física e doutorando do Programa de Pós Graduação em Geografia Física da Universidade de São Pau lo. Email: rvervloet@usp.br

${ }^{2}$ Geógrafo, Mestre e Doutor em Geografia Física, Professor titular do Departamento de Geografia da Universidade de São Paulo - E-mail: juraross@usp.br

DOI: 10.7154/RDG.2012.0023.0008
} 
mainly associated with tectonic geomorphic elements. And lastly, there are studies highlighting the formation through geochemical processes and even the geomorphic features of planed surfaces built up between the major compartments of regional reliefs (Serra do Mar and Mantiqueira). The conclusion is that none of these lines alone is able to fully explain the geomorphic genesis of the Plateau, remaining unknowns that challenge old approaches. New questions arise and old ones persist, across period to period and school to school.

Key-Words: Atlantic Plateau; Tectonics; Surface of Planation; genesis of relief.

\section{INTRODUÇÃO}

A formação de uma verdadeira escola de geociências no Brasil teve início com as primeiras indagações científicas sobre a origem do relevo que caracteriza a totalidade do conjunto de serras e planaltos do Brasil Atlântico. Quase todo o processo de investigação e formação de pensadores da nossa escola geocientífica, em uma fase embrionária, esteve, de uma forma ou de outra, relacionado à tentativa de compreensão dos processos geológicos e geomorfológicos responsáveis pela origem desses planaltos de fachada. Como várias vezes ocorre na história das ciências, grandes temas de investigação delega a formação de escolas de pensadores. Assim, não é difícil afirmar que os trabalhos mais clássicos das geociências brasileiras estão relacionados ao entendimento da compartimentação geomorfológica, estruturação geológica e tectônica, ciclos erosivos de aplainamento, ritmos e pulsos tectônicos e processos de erosão diferencial que foram responsáveis pela esculturação das serras e escarpas que caracterizam todo o relevo do Planalto Atlântico.

A implantação das primeiras universidades no Brasil, junto com a chegada de pesquisadores estrangeiros da área geocientífica, possibilitou que o Planalto Atlântico fosse estudado em seus diversos temas e nos mais amplos setores, desde os vales tectônicos do Rio Paraíba do Sul e Baía da Guanabara até os Planaltos da Mantiqueira Setentrional na divisa entre os estados de Minas Gerais, Rio de Janeiro e São Paulo, passando pelos vales do Rio Ribeira de Iguape até os planaltos escalonados do Paraná. Uma verdadeira área de fachada, com escala territorial imensa, englobando grande parte da costa brasileira e sua hinterlândia imediata. Assim, é considerado como Planalto Atlântico neste artigo todo o conjunto de terras altas que caracterizam as serras, depressões embutidas, vales tectônicos, escarpas de falha, cadeia de morros escalonados, superfícies interplanálticas e aplainadas, e superfícies de cimeira que ocorrem ao longo da fachada atlântica, desde Paraná passando pelos Estados de 
São Paulo e Rio de Janeiro até o norte do Espírito Santo, onde esta localizada a chamada Região Serrana deste Estado.

Tais setores de Planaltos são comumente tratados na literatura como Serra do Mar quando próximos ao litoral, e Serra da Mantiqueira quando adentrando para o interior do Sudeste, ou com nomes de expressões locais como Serra dos Órgãos, que é um setor da Serra do Mar no Rio de Janeiro, ou Serra de Paranapiacaba que se configura como outro setor da mesma serra em São Paulo.

Na construção da escola de pensamento geocientífica brasileira, que esteve num primeiro momento muito preocupada em compreender essas terras altas e iniciada na década de 30, houve o estímulo de amplos debates entre geólogos e geomorfológos de vanguarda. Neste contexto, dois temas mereceram maior destaque nas discussões, a compartimentação geomorfológica dos Planaltos que compõe as terras altas do Brasil Atlântico e os processos de erosão diferencial e de aplainamento atuantes sobre o embasamento cristalino que sustentam os mesmos. A Tectônica Cenozóica e de Deslocamento de Blocos, com ativação de falhas Proterozóicas, foi também de grande destaque, tendo merecido atenções sistemáticas a partir dos anos 70, quando se desenvolve no Brasil uma abordagem geológica fundamentada na tectônica de placas, embora na década de 50 já houvessem trabalhos com uma visão pioneira por meio de uma interpretação com abordagem predominantemente tectônica na gênese desses planaltos (FREITAS, 1951a, 1951b;RUELLAN, 1944).

Atualmente existe um rico e considerável acervo de trabalhos sobre as mais diferentes óticas e abordagens, tanto geológica quanto geomorfológica, sobre o Planalto Atlântico Brasileiro ou porções setorizadas. É a partir da existência dessa multiplicidade de enfoques que este artigo tenta identificar e reconhecer quatro correntes de estudos que caracterizam o estado atual de conhecimentos sobre o Planalto Atlântico. Em primeiro lugar há uma corrente que trabalha com modelos geomorfológicos erosivos com implicações tectônicas, em segundo é possível verificar outra com enfoque morfoclimático baseado nas mudanças climáticas Quaternárias, em terceiro lugar há uma seqüência de pesquisas que não é fundamentalmente geomorfológica, mas de enfoque predominantemente tectônico associado com elementos geomórficos, e, por último, há trabalhos destacando a formação por processos geoquímicos das feições geomórficas $e$ até as superfícies aplainadas embutidas entre os grandes compartimentos de relevos regionais (Serra do Mar e Mantiqueira). Este artigo tem como objetivo, portanto, verificar o estado atual dos 
conhecimentos sobre o relevo do Planalto Atlântico, através do que é apresentado pela literatura, começando pela primeira corrente de interpretaçao e seguindo a seqüência histórica dos trabalhos que caracterizam cada modelo de explicação, inerentes às diversas correntes aqui relatadas.

\section{MATERIAIS E MÉTODOS}

Para elaborar esta revisão dos conhecimentos sobre o Planalto Atlântico, seguimos como metodologia de seleção bibliográfica, consultar trabalhos que tratassem, genuinamente, dos relevos do Planalto no que diz respeito a sua compartimentação geomorfológica, tectônica, processos genéticos e evidências da atuação paleoclimática Terciária. Procuramos dar ênfase a uma seqüência de trabalhos iniciais consagrados, procurando na bibliografia seguinte aos mesmos, a continuidade das diretrizes e pontos levantados, ou seja, as tentativas de respostas às indagações apresentadas. Assim, os conhecimentos que eram gerados pelos métodos e conceitos desenvolvidos pelas pesquisas iniciais eram postos em dúvidas, abrindo novas linhas de tratamento e busca de desenvolvimento teórico das correntes. Procuramos periodizar tais trabalhos em quatros correntes históricas - que já foram citadas anteriormente - para facilitar a identificação das linhas de raciocínios estabelecidas.

\section{RESULTADOS E DISCUSSÃO}

\section{Os modelos geomorfológicos erosivos com implicações tectônicas.}

O primeiro grande trabalho de interpretação geomorfológica erosiva com implicações tectônicas sobre o relevo do Planalto Atlântico deve-se a Moraes Rego (1933), quem discutiu a evolução geomorfológica do Estado de São Paulo, a partir de uma ótica fundamentada na atuação de processos de erosão diferencial influenciado por movimentos tectônicos. Dizia Moraes Rego (1933, p.10),

Com a organização da rede de drenagem para oeste, com nível de base abaixo dos anteriores, atuou a erosão diferencial, no sentido de escavar a depressão periférica, e de destacar escarpas sustentadas por rochas mais resistentes, como basaltos, constituindo um relevo de cuestas. Dessa fase de escavação restaram testemunhos como a Serra de Angatuba e as elevações situadas entre o Piracicaba e o Tiete. Os rios conseqüentes mais 
importantes progrediram epigeneticamente, ao passo que, outros foram capturados pelos afluentes subseqüentes.

Este autor destacava também que o Vale do Paraíba era resultado da atuação de processos erosivos sobre gnaisses menos resistentes, fato que mais tarde comprovou-se como de abordagem equivocada.

Para Moraes Rego, a tectônica que atuava em suas interpretações era, sobretudo, de natureza epirogenética quando provocava levantamento de toda a topografia estimulando a retomada de ciclos erosivos. Esta visão era fundamentada na ausência de afloramentos onde fosse possível visualizar camadas de rochas extensivamente perturbadas, o que levava este autor a acreditar que a tectônica responsável pelo soerguimento dos Planaltos fosse oriunda de uma epirogênese positiva, contrária à visão de natureza orogenética na dinâmica tectônica. Para a dissecação dos terrenos do Planalto, ele advogava a idéia da atuação de ciclos erosivos de aplainamento sobre as estruturas litológicas heterogêneas, estabelecendo a diversidade de compartimentos morfológicos escalonados que caracterizam as terras altas do Brasil atlântico.

Mais tarde foram publicados em nosso país dois artigos de De Martonne $(1943,1944)$, onde se percebe como questão central no seu trabalho estabelecer os pesos relativos da erosão diferencial e da tectônica na explicação do desenvolvimento das formas de relevo do Planalto Atlântico. De Martonne já especulava na década de 40, sobre uma possível tectônica de blocos falhados atuante com ciclos erosivos de aplainamento. Ele argumentava da seguinte forma,

O "fosso do Paraíba" é talvez uma hipótese simples demais. O rio, como os lagos alongados que o precederam no Terciário, parece instalado ao pé de um abrupto tectônico, flexura decomposta em escadaria de falhas marcando a borda de um bloco basculado para o norte, da mesma maneira que o bloco da Serra do Mar (DE MARTONNE, 1943, p.530).

Sua hipótese contrastava desta maneira com a de Moraes Rego (op. cit,), para quem o vale do Paraíba era oriundo de erosão diferencial sobre gnaisses menos resistentes. Para De Martonne, as serras costeiras, a Serra da Mantiqueira e todo o Vale do Paraíba tinham uma origem tectônica, proveniente do deslocamento de blocos falhados. Seu modelo de explicação era fundamentado na atuação de ciclos erosivos de aplainamento conjugado com a tectônica responsável pelos deslocamentos verticais dos blocos falhados. Na sua interpretação, as grandes escarpas e abruptos que caracterizam as serras do Mar e da 
Mantiqueira teriam origem por tectônica de movimento desses blocos falhados, gerando as denominadas escarpas de falha. Estes dois trabalhos de De Martonne podem ser considerados como o pontapé inicial de profundas discussões que continuam até hoje, pois o mesmo identificou quatro superfícies de aplainamento que ainda estimulam acalorados debates na geomorfologia brasileira.

Em suas hipóteses, num primeiro momento, De Martonne (op. cit,) identifica uma superfície fóssil que ele denomina de Superfície Pré-Permiana, ao fazer excursões nas redondezas de Itu no interior de São Paulo. Depois, ao fazer excursões por Campos do Jordão, Campos de Paraíso e Campos de Ribeirão Fundo, em São Paulo, ele identifica uma outra superfície a qual denomina de Superfície dos Campos, que considera como mais recente que a Superfície Pré-Permiana. Na região de Moji-Guaçu ele visualiza um nível de colinas mamelonares e cristas curtas, com orientações as mais diversas que denomina como Superfície das Cristas Médias, e por último, ao fazer trabalhos de campo pela região de Pouso Alegre em Minas até Campinas no interior de São Paulo, ele identifica uma outra superfície que passa a denominar de Superfície Neogênica, que mais tarde será também identificada, mapeada e muito bem estudada, em São José dos Campos, por Coltrinari (1974, 1992 e 2002).

A Superfície Pré-Permiana foi, posteriormente, identificada também por Rich (1953) na região de Itu, Salto e leste de Sorocaba no interior de São Paulo. Trabalhos realizados sequencialmente aos de De Martonne procuraram pesquisar essas superfícies, travando amplas discussões que se desenrolam atualmente.

Após De Martonne, aparece o trabalho de Ruellan (1944) sobre a baía da Guanabara e regiões vizinhas, onde através de uma visualização geomorfológica das Serras do Mar e da Mantiqueira, a moda de compartimentos, ele caracteriza as mesmas como frentes dissecadas de blocos falhados e basculados para norte. Seu raciocínio era o seguinte,

A situação da Guanabara entre o rebordo meridional falhado da Serra dos Órgãos e os maciços litorâneos, faz com que logo se pense num bloco falhado abaixado ou numa depressão de ângulo de falha. A descoberta de uma antiga pequena bacia fechada no município de Itaboraí é um fato importante em favor desta hipótese (RUELLAN op. cit, p.457).

Ruellan também destaca que a Baía da Guanabara teria passado por uma fase prévia de erosão, acreditando tal fato ter ocorrido quando o nível do mar estivesse mais baixo, associando esta regressão marinha aos efeitos dos estágios glaciais e interglaciais que eram estudados no hemisfério norte. Chegou a tal hipótese, ao delimitar e mapear os paleovales 
da própria baía, atualmente submersos. Portanto, Ruellan também pode ser considerado como um exemplo claro da associação de processos erosivos com tectônicos na interpretação dos blocos elevados do Planalto Atlântico.

Outro autor que caracteriza bem este modelo de explicação da geomorfologia do Planalto atlântico é Freitas (1951a, 1951b). A interpretação de Freitas (1951a) é uma das mais elucidativas sobre este sistema de explicação, projetado através de aguçadas observações. Sua tese central era,

O complexo cristalino brasileiro constitui a zona de interesse para observar as superfícies de erosão policíclicas, sendo secundária a sua extensão nas séries sedimentares do interior, onde a erosão diferencial complica o problema... A existência de dois peneplanos marcados na topografia do escudo cristalino corresponde a uma variação geral no nível de base da hidrografia, cujo significado exprime recorrência de levantamentos epeirogênicos, únicos capazes de afetar regionalmente a hidrografia, provocando novo ciclo de erosão (FREITAS, 1951a, p. 5).

Os dois peneplanos eram denominados por A e B, um situado entre 800 a 1.000 metros de altitude e em posição mais inferior e, era, portanto, mais recente, e o outro entre 1200 a 1400 metros, que por ser superior altimetricamente, seria, por sua vez, mais antigo. Esses dois peneplanos eram o resultado de ciclos erosivos iniciados por mudanças no nível de base, dado pela hidrografia após levantamentos epirogenéticos positivos.

Freitas contrariava totalmente a tese de De Martonne sobre a existência de uma superfície como a Superfície dos Campos. Para ele, esta seria o peneplano de nível B, desnivelado e fraturado em diferentes cotas, devido aos movimentos dos rejeitos dos blocos falhados. De Martonne anotava em perfis a presença dessas falhas, mas não se referia a elas como responsáveis pelo esfacelamento de uma única superfície sotoposta a diferentes cotas de altitude, questão levantada por Freitas a qual De Martonne não faz nenhuma alusão.

Essa suposição empírica vai ser retomada depois, por meio de uma hipótese a ser investigada através de uma pesquisa bem sistematizada, por Almeida (1964b). Este autor procura avançar na tese levantada por Freitas, porém colocando novas indagações e limites na idade das superfícies. Ele embasa suas idéias na linha dos processos de erosão diferencial, dado pela diversidade litológica das estruturas, e com ciclos erosivos acompanhados de eventos tectônicos, tendo uma consideração relativa sobre a influência paleoclimática na gênese dos compartimentos do Planalto. A citação abaixo de seu trabalho de 1964 demonstra bem sua linha de raciocínio, 
“... é de se crer que pelo menos desde o neogêneo venham nele se manifestando climas tropicais úmidos, embora com possíveis oscilações quanto as características absolutas de seus fatores. O relevo atual bem reflete a ação de tais climas, nas suas formas generalizadamente suavizadas, na presença de profundos mantos de alteração, na evolução laterítica de seus solos com concentrações aluviais originando crostas e carapaças limoníticas, bauxíticas ou de outros hidrolisatos" (ALMEIDA, 1964b, p. 171).

Ele estabelece também os limites do conhecimento das superfícies com relação às suas idades e formas de evolução,

“...nada se conhece, em São Paulo, de coberturas originais das superfícies pós-paleozóicas. ...Assim sendo, parece-nos prematuro discutir a origem de tais superfícies, pelo risco de resvalar-se facilmente para o perigoso domínio da fantasia. Assim sendo, não aplicaremos a elas as denominações genéticas de peneplanícies, pediplanícies ou outras, mas as designaremos simplesmente como superfícies de aplainamento, ou de erosão, atribuindoIhes nomes geográficos" (ALMEIDA, op.cit, p. 173).

É dessa forma que ele vai denominar como Superfície Itaguá a Superfície Pré-Permiana de De Martonne, e a Superfície dos Campos ele nomeia como Superfície Japi. Ao endossar a tese de Freitas destaca que a Superfície dos Campos e a do Japi teriam sido uma única superfície, posta a diferentes cotas de altitude pela tectônica de rifteamento que deu origem aos sistemas de riftes que caracterizam os vales ao longo do Rio Paraíba do Sul. Ele continua aperfeiçoando as evidências desta tese em três trabalhos posteriores, (ALMEIDA, 1976; PONÇANO; ALMEIDA, 1993; ALMEIDA; CARNEIRO, 1998), onde conclui explicitamente não ser os relevos que caracterizam as serras do Mar e da Mantiqueira, oriundos de neotectônica, mas de processos erosivos atuantes em zonas de fraqueza, dado pelos sistemas de falhas e pelo recuo das escarpas nos últimos milhares de anos, após eventos tectônicos de soerguimento e rifteamento dos blocos que vieram a formar os Planaltos, atuantes no Paleógeno.

Almeida (1964a e 1976), Ponçano e Almeida (1993) e Almeida e Carneiro (1998), também destacam a ocorrência de ciclos erosivos posteriores aos processos responsáveis pela formação da Superfície Japi, que deram origem aos planaltos embutidos e mais rebaixados. Tal fato havia sido revelado por De Martonne e Moraes Rego, no entanto, com interpretação diferente das sugeridas por esses autores. Almeida não acredita serem esses planaltos embutidos, originados por processos de planação lateral, nem acidentes tectônicos, "...Tais desníveis não são devidos a acidentes tectônicos, mas acham-se relacionados com a 
importância e extensão dos rios que as drenam, a resistência das rochas de suas bacias e das que nelas constituem soleiras" (ALMEIDA, op. cit. p. 177-178) esta é a sua conclusão.

Dois trabalhos de grande vulto que caracterizam bem esta corrente são os de $A b^{\prime}$ Sáber (1964) que coloca problemas de grande complexidade na tentativa de entendimento do relevo atlântico, mas em uma escala projetada para todo o território nacional, e, o trabalho de King (1956) que realizou excursões por toda a fachada atlântica, tentando identificar e mapear os quatros ciclos de desnudação designados por ele de Gondwana, Pós-Gondwana, Sul-Americano, Velhas e Paraguaçu, sempre acompanhado de movimentos epirogênicos positivos.

O trabalho de Azevedo Júnior (1991) que assim como Ponçano e Almeida (1993) e Almeida e Carneiro (1998) considera a Serra do Mar como um compartimento topográfico residual derivado do recuo, continente adentro, da frente erosiva atuante nos blocos falhados do Planalto Atlântico, também segue a ótica dos processos erosivos com implicações da tectônica.

Ross (1992 e 1991) e Vervloet (2009) seguem a mesma linha de raciocínio de Almeida e Carneiro (op. cit,) trabalhando com a idéia de evolução dos compartimentos dado por processos químicos atuantes em estruturas litológicas de grande heterogeneidade mineralógica, havendo neste sentido, maior peso a diversidade litológica como responsável pela multiplicidade de compartimentos.

Todos esses trabalhos citados procuraram explicar o relevo atlântico por meio de uma abordagem interpretativa com atuação de processos erosivos sobre estruturas fortemente anisotrópicas, tendo a tectônica Cenozóica como elemento "auxiliar" na explicação genética, entretanto, com maior peso as variáveis e processos de erosão diferencial, dando relativa participação as influências paleoclimáticas na evolução do Planalto. Por não responder plenamente as indagações surgidas no debate geológico e geomorfológico, permanentemente presente, eles abriram as possibilidades para o estabelecimento e fundação de uma escola de abordagem morfoclimática, através de questões deixadas em aberto. 


\section{A abordagem morfoclimática e as mudanças climáticas Terciárias.}

A tentativa de compreensão da origem do relevo atlântico por meio de interpretações com predomínio de abordagem morfoclimática e paleoclimatológica teve suas primeiras inquirições através do segundo artigo de De Martonne (1944). Neste trabalho ele identifica os relevos que possuem determinadas características condizentes com as condições morfoclimáticas em que estão inseridos, e evidências da atuação de oscilações climáticas na gênese dos mesmos.

Após De Martonne, aparece Ruellan $(1944,1952)$ com suposições mais embasadas sobre os efeitos das oscilações climáticas Quaternárias na gênese dos compartimentos do aludido Planalto. Ruellan (op. cit,), no entanto, não avançou muito em suas indagações, servindo, entretanto, de base para Ab'Sáber (1957) tecer fortes considerações sobre a importância paleoclimática na formação dos relevos que caracterizam tal conjunto planáltico. Embora Ruellan e De Martonne tenham colocado importantes considerações sobre climas passados na formação destes relevos, apresentam somente evidências sem grandes aplicações de métodos e técnicas de pesquisas estratigráficas para se investigar tais evidências. Todavia, eles deixam as bases para a aplicação do método estratigráfico dos depósitos correlativos, que embasou uma série de trabalhos a partir dos anos 60.

A formação de uma verdadeira escola morfoclimática, embasada em um modelo teórico e com evidências estratigráficas de campo para se procurar entender a gênese do relevo atlântico e de outras partes do Brasil sudeste, inicia-se a partir da década de 1960, com os trabalhos de Bigarella e Ab'Sáber (1961), Bigarella e Mousinho (1965), Bigarella, Mousinho e Silva (1965a, 1965b), Bigarella e Andrade (1965), Ab’Sáber (1969a, 1969b, 1969c, 1969d e 1969e), e Bigarella, Andrade Lima e Riehs (1975).

A linhagem teórica apresentada por estes trabalhos tornou-se o paradigma de grande parte dos geomorfólogos brasileiros. A corrente paleoclimática consegue conjugar perfeitamente processos erosivos e deposicionais com formas de relevo, através de sucessões temporais bem definidas dentro do Quaternário.

Estes autores partiam do princípio de que nos períodos glaciais o clima da fachada atlântica do Brasil de sudeste seria mais seco, com características áridas nas depressões interplanálticas e semi-áridas a sub-úmidas nas regiões mais escarpadas e setores de planaltos, havendo uma paisagem praticamente sem solos em certo setores, destituída de 
cobertura vegetal mais densa e processos torrenciais localizados (resistasia), similares aos climas semi-áridos e sub-úmidos, ao passo que nas épocas inter-glaciais, a paisagem evoluía por processos morfoclimáticos com características úmidas (biostasia), com cobertura vegetal densa e solos profundos, desenvolvidos por intemperismo predominantemente químico. Havia neste sentido, uma grande influência da teoria biostásica e resistásica do pedólogo Erhart (1956).

Partindo deste esquema de interpretação ocorreriam fases de mudanças drásticas nas condições dos processos geomórficos de evolução da paisagem durante o Quaternário, com forte ruptura na dinâmica dos mesmos ao longo de todo Planalto Atlântico. Vários outros pesquisadores tentaram aplicar em escala regional e local os modelos preconizados por essa linhagem, uma vez que ela enfocava de modo estratigráfico as etapas geomorfogenéticas permitindo, em decorrência, uma compreensão aparentemente mais precisa da evolução do relevo.

Para estes autores, o final do cretáceo teve como repercussão a deposição de uma grande superfície derivada do desenvolvimento de um grande pediplano, cujos depósitos correlativos são encontrados na parte superior das seqüências cretáceas como a Série Bauru que ocorre no interior de São Paulo. Esta superfície foi denominada de $P d 3$, que teria sido falhada e arqueada, tendo como resultante os blocos montanhosos da Serra do Mar, acentuados por processos erosivos e tectônicos, conforme Bigarella e Ab'Sáber (1961) e Bigarella, Marques e Ab’Sáber (1961). No Terciário médio um novo aplainamento teria gerado uma outra superfície denominada de $P d 2$, de natureza intermontana e periférica, entretanto, sem depósitos correlativos, e entre o Plioceno e Pleistoceno, teria sido desenvolvida a mais recente superfície de aplainamento do país chamada de $P d 1$, que em algumas regiões é conhecida como superfície neogênica, correspondendo a mesma Superfície Neogênica que De Martonne (1943) identificara na depressão periférica paulista, junto com Penteado (1968) e Modenesi (1974).

Na corrente paleoclimática preconizada nestes trabalhos, a tectônica atuante é sempre de natureza epirogenética positiva, sem grande deslocamento de blocos falhados, não sendo neste sentido, o grande fator formador dos compartimentos de relevo do Planalto Atlântico. Sua gênese é tomada somente como variável relativa de explicação, sendo, muitas vezes, solicitada somente no momento em que as oscilações paleoclimáticas Quaternárias não 
estabelecem uma plena e confiável elucidação dos problemas geomórficos relacionados aos relevos do Planalto.

Em outras partes do Brasil vários outros autores tentaram aplicar o modelo morfoclimático e paleoclimático com ligeiras modificações, acompanhados de métodos e técnicas mais refinadas e cartografia em escala mais detalhada, com tentativas de datações de depósitos de colúvio e outros registros sedimentares correlacionados as feições do relevo, através de C14. Entretanto, o fundamento da abordagem sempre é o mesmo, o da tentativa de se entender os compartimentos geomórficos fundamentados em mudanças paleoclimáticas Quaternárias. Tais trabalhos são os de Moura e Silva (2001), Meis e Moura (1984), Melo et al (1987), Moura (1990), Moura et al (1992), Moura e Mello (1991), Meis (1977), Mello (1992) e Bistrichi (2001), entre outros. Eles acabam seguindo a ótica dos trabalhos realizados na década de 1960, identificando, também, fases de instabilidade e estabilidade nas paisagens planálticas, sendo que os trabalhos de Mello (1992), Melo et al. (1987) e Moura e Mello (1991) correlacionaram as fases de desequilíbrio da paisagem à gênese da Aloformação Manso, unidade aloestratigráfica ocorrente nos domínios de encostas e vales fluviais na região do médio vale do Rio Paraíba do Sul. Tais idéias corroboraram a ruptura nas condições dos processos geomórficos da paisagem identificados na década de 60, com maior nível de detalhe no que diz respeito à datação e associação do registro sedimentar com os relevos correlativos.

Há entre os vários autores, divergências quanto a posição cronológica das superfícies, como Ab'Sáber (1969e) diverge de Bigarella e Andrade (1965), e há também discordâncias com relação a própria dinâmica erosiva decorrente das oscilações climáticas e tipos e características dos processos ensejados em cada período climático, como Meis e Moura (1984) contrastam com Bistrichi (2001). Entretanto, o fundamento da linha de tratamento permanece a mesma, ou seja, continua-se utilizando como variável fundamental de explicação, a atuação de paleoclimas na gênese dos compartimentos e superfícies embutidas no Planalto Atlântico, tendo as variáveis tectônicas um papel secundário na compartimentação das terras do Planalto.

Todavia, devemos salientar que em função dos trabalhos realizados, das técnicas modernas de datação que, até então estão sendo utilizadas, dos métodos estratigráficos e geomorfológicos aplicados, e, a vista dos conhecimentos acumulados, não resta dúvida de que realmente houve oscilações climáticas durante todo o Terciário, e que as mesmas 
influenciaram fortemente a gênese e os processos responsáveis pelo relevo do Planalto Atlântico. Entretanto, há que se ponderar melhor os fatores e os processos envolvidos na constituição dos compartimentos geomórficos do mesmo, pois ao final dos anos 80 e início dos anos 90, uma série de trabalhos vão enfatizar uma maior participação da tectônica nesta constituição, com o objetivo de se entender melhor os processos responsáveis pela compartimentação dos grandes blocos, escarpas e desníveis altimétricos que ocorrem nas terras altas que configuram a fachada atlântica do Brasil.

Contudo, há autores como Bigarella e Ab'Sáber que não abandonam o modelo teórico assentado nas oscilações climáticas Quaternárias, publicando outros trabalhos que adicionam informações paleoecológicas e biogeográficas, tratando não somente de questões ligadas ao relevo, mas de temas da biogeografia, zoogeografia, sedimentologia e pedologia (AB'SÁBER, 1980, 1984, 1989, 1993, BIGARELLA, 2007a, 2007b e 2003). Portanto, configurase a linha dos estudos morfoclimáticos não somente para explicação de fatos geomorfológicos e geológicos, mas de questões ligada a ecologia e biogeografia das paisagens tropicais, havendo uma forte interação no campo dos estudos inter e multidisciplinares. Todavia, esta tem se chocado fortemente com a corrente predominantemente tectônica.

\section{A predominância da tectônica associado com elementos geomorfológicos.}

Esta linhagem de estudos que caracterizam um grupo diverso de trabalhos de pesquisa sobre o Planalto Atlântico não deve ser posicionada, necessariamente, como pertencente ao campo da geomorfologia stricto sensu. Trata-se, aliás, de investigações de natureza geológico-tectônica que fizeram, ao mesmo tempo, uso de elementos geomórficos com o objetivo de entender melhor a natureza e dinâmica da tectônica atuante na gênese das bacias sedimentares da margem continental e das terras altas do Planalto, em especial o seu papel como área fonte de sedimentos para as bacias de Campos, Espírito Santo e Santos e outras questões correlacionadas.

Os primeiros trabalhos nesta ótica foram publicados no início da década de 70 , quando se iniciava no Brasil, uma série de pesquisas fundamentados na teoria da tectônica de placas, objetivando reconhecer, mapear e compreender melhor a margem continental atlântica em função das bacias sedimentares aí instaladas, e prováveis reservas de hidrocarboneto 
descobertas nesta época e confirmadas posteriormente. Portanto, a grande incentivadora dos trabalhos que fazem uso predominante das variáveis tectônicas foram as pesquisas associadas a investigação sobre reservas de hidrocarboneto ligadas a industria do petróleo. As primeiras pesquisas nesta linha foram os trabalhos de Asmus et al (1971), Estrella (1972), Asmus (1975) e Asmus e Ferrari (1978). Estas pesquisas levantaram a hipótese de que haveria um soerguimento crustal derivado de um intumescimento na crosta que teria como conseqüência a formação de um grande domo induzido, provavelmente, por anomalias tectono-térmicas no manto, em estágio pré-rifte. Como resposta, houve adelgaçamento crustal acompanhado de intensa erosão da área soerguida, ao que se seguiu a ruptura crustal no Eocretáceo. O afastamento dos continentes, separados pelo rift valley, teria ocasionado a subsidência da margem pelo resfriamento da crosta e sobrecarga dos sedimentos.

O aparecimento dos riftes da região sudeste seriam, por sua vez, uma provável conseqüência do referido soerguimento da região, e ter-se-ía processado por falhamentos escalonados e basculados de blocos, confirmado em Almeida (1976) e Asmus e Ferrari (1978). Mais tarde, outros trabalhos realizados descobriram que essas falhas eram do Proterozóico, tendo passado por fases de reativação a o longo do Cenozóico, conforme Hasui (1990). O soerguimento responsável pela elevação das terras do Planalto teria sido anterior a formação das bacias tafrogênicas do vale do Rio Paraíba do Sul, sendo ocorrente em fases posteriores por reativações e afetando os próprios depósitos. Estes trabalhos avançaram em muito por meio do conhecimento do que se tinha na época, lançando proposições que foram confirmadas posteriormente com ligeiras modificações.

No final dos anos de 1970 e início dos 1980, o estudo do preenchimento sedimentar das Bacias Terciárias continentais do vale do Rio Paraíba do Sul desenvolve-se através de trabalhos com maior nível de detalhe, e de modelos de evolução tectono-sedimentar, mais especificamente as bacias de São Paulo, Taubaté, Resende e Volta Redonda, conforme Hasui e Ponçano (1978), IPT (1983), Melo et al. (1985) e Riccomini (1989). Apesar destes trabalhos serem de natureza, predominantemente tectônica e sedimentar, apresentando uma complexidade crescente quanto à descrição de ambientes de sedimentação e a inferências de ordem tectônica, eles tendem, no que diz respeito aos paradigmas geomorfológicos anteriores, a confirmar as proposições iniciais de De Martonne (1940) e Ruellan (1944), com relação à organização de blocos falhados e basculados para noroeste, e em relação ao fato 
de haver um papel maior da tectônica na compartimentação dos Planaltos, idéia não muito aceita pelos autores da linhagem da geomorfologia climática. No entanto, eles não fazem menção a existência de superfícies de aplainamento embutidas nos compartimentos do Planalto, como faz saber De Martonne (op. cit.), relembrado por Ab’Sáber (1964, 1969e), Bigarella e Ab'Sáber (1961), Bigarella e Andrade (1965), e Bigarella, Andrade Lima e Riehs (1975), Modenesi (1974) e confirmados nos trabalhos mais recentes de Coltrinari (1992, 2002). Os mesmos também não fazem ensaios de compartimentação geomorfológica.

Estes autores também trabalham com a hipótese de que os eventos tectônicos nestas bacias terciárias não terminaram no Terciário e várias outras pesquisas têm demonstrado que as falhas principais continuam ativas até os dias atuais, fortalecendo uma linha de pesquisa que trabalha sobre a ótica dos estudos de neoctectônica.

Para Riccomini (op. cit.) e Riccomini et. al. (2004), o Rift Continental do Sudeste do Brasil, antes chamado de Sistemas de Rifts Continentais da Serra do Mar por Almeida (1976), e que segundo Melo et al (1985) compreende as bacias de Curitiba, São Paulo, Taubaté, Resende e Volta Redonda, seria um testemunho do papel da neotectônica na evolução das terras do Planalto. Trabalhos elaborados em partes isoladas do Planalto, como nos Planaltos da Bocaina, foram executados dentro desta ótica, como os de Gontijo (1999) e Hiruma (2007), e na Guanabara por Ferrari (2001). Nestes trabalhos sempre fica implícita a idéia de que as terras altas teriam origem no Paleógeno, continuando ativa durante o Neógeno e Quaternário até os dias atuais, constituindo reflexos interiores e tardios da Reativação Wealdeniana de Almeida (1969) ou evento Sul - Atlântico de Schobbenhaus et. al. (1984), ou ainda Reativação Pós-Paleozóica de Almeida (1988).

Salvador e Riccomini (1995) e Mancini (1995) também se dirigem nesta mesma interpretação, só que pesquisando aspectos entre a neotectônica e a estratigrafia das bacias terciárias do Rio Paraíba do Sul. Em outras regiões do Brasil Saadi (1993) também trabalhou dentro da abordagem neotectônica, como nos tabuleiros do sul da Bahia e região de São João Del Rey no sul de Minas Gerais, projetando tal linha de tratamento na proposição denominada de ativação da plataforma brasileira (SAADI, op. cit,).

Há uma divergência entre os modelos erosivos de implicações tectônicas muito bem endossado por Almeida (1976), Ponçano e Almeida (1993), Almeida e Carneiro (1998), e o modelo de predominância tectônica preconizado pelos trabalhos neotectônicos de Riccomini (op. cit.), Riccomini et al (2004), Gontijo (1999), Hiruma (2007), Ferrari (2001), Hasui (1990), 
Saadi (1993), Salvador e Riccomini (1995) e Mancini (1995). Nos primeiros trabalhos a tectônica atuante teria se iniciado no Paleógeno, soerguendo os compartimentos do Planalto e provocando o rifteamento dos blocos, e sendo os relevos atuais do mesmo, grandes feições residuais ocasionados pelos processos erosivos atuantes nos últimos milhares de anos. Para os segundos, que são considerados como "neotectonistas", haveria sim, amplos processos erosivos ocorrentes nos últimos milhares de anos, mas em uma escala de importância menor, se comparado aos eventos neotectônicos que teriam se iniciado por reativação das estruturas Proterozóicas antigas, também a partir do Paleógeno. Esta reativação teria sua gênese ligada ao rifteamento, provocando o deslocamento dos blocos falhados (tectônica de dominó) e continuando os movimentos das falhas até os dias atuais, como é possível observar em afloramentos de depósitos sedimentares recentes que tais trabalhos documentam e registram nos vales, planícies e terraços do Rio Paraíba do Sul e outros setores do Planalto. Para os "neotectonistas", as terras altas do Planalto não seriam somente macro-feições residuais, mas constituiriam blocos morfotectônicos soerguidos diferencialmente a distintas cotas altimétricas. No que diz respeito à existência de deslocamento tectônico das superfícies aplainadas de cimeira, todos estão em concordância com Freitas (1951), ou seja, procuram corroborar a tese da existência de uma paleosuperfície do passado posta a diferentes cotas pelos desmantelamento e fragmentação, oriundo da reativação das falhas.

Em uma pesquisa sobre os recursos energéticos associados à ativação tectônica Mesozóico Cenozóica da América do Sul, Mohriak (2004) acaba endossando o modelo preconizado pelos trabalhos de Almeida, ao estudar as bacias sedimentares de Santos, Campos e Espírito Santo. Entretanto, Zalán e Oliveira (2005) contestam tal interpretação, apresentando novos elementos baseados em dados de geofísica e de geomorfologia, corroborando parte do que foi proposto por trabalhos anteriores de neotectônica, e dando grande ênfase a "tectônica moderna', ao tentar explicar a diferenciação altimétrica dos compartimentos do Planalto. No entender destes autores, o regime tectônico atuante e responsável pelos vales do Paraíba, serras do Mar e da Mantiqueira, assim como o restante das terras altas do Planalto, atuaria desde o Cenozóico, sendo distensional e predominantemente perpendicular (mecanismo de deformação por cisalhamento puro) a ligeiramente oblíquo, sendo responsável pela implantação de uma suave transtensão sinistral que moldou rombo-grábens e escalonou sutilmente à direita os grábens mais orientais e mais offshore. 
Zalán e Oliveira (op.cit.) também acreditam, assim como era colocado por Freitas (1951), que as superfícies cimeiras (Superfície Japi) seriam uma só mega superfície soerguida as diferentes cotas de altitude por essa tectônica atuante ao longo do Cenozóico. Todavia, eles não fazem muita menção as superfícies embutidas e interplanálticas existentes ao longo dos grandes vales e depressão periférica paulista. Quando o fazem, consideram estas como blocos pertencentes a uma mesma superfície pretérita (Japi), posicionada em várias cotas de altitude pela tectônica Cenozóica.

De certa forma, não há nos trabalhos que preconizam a atuação da tectônica moderna (neotectônica) - como variável fundamental para se entender a compartimentação geomorfológica atual do Planalto Brasileiro - muita menção sobre a importância das superfícies de aplainamento embutidas nas depressões interplanálticas e vales intermontanos, como foi identificado pelos trabalhos de Ab'Sáber e Bigarella na década de 60, pesquisadas por Modenesi (1974) e Coltrinari (1974, 1992 e 2002). Embora não fosse objetivo dos mesmos estudar a geomorfologia stricto sensu das diversas áreas do Planalto, o problema das superfícies embutidas e relevos intermontanos, coloca importantes indagações sobre o papel da "tectônica moderna" na formação de todos os desníveis altimétricos encontrados ao longo de diversos setores do Planalto, e sobre os ciclos erosivos contemporâneos às etapas e ao tempo de soerguimento dos blocos que sustentam as terras altas do Planalto, questão muito bem levantada por Ponçano e Almeida (1993).

\section{As superfícies embutidas e os relevos originados por processos geoquímicos.}

A identificação de superfícies embutidas remonta aos trabalhos de De Martonne (1943, 1944), quem primeiro estudou as mesmas no interior de São Paulo, se referindo a elas como as mais recentes, estando posicionadas no Neógeno. Ao fazer excursões pela região de Campinas, este autor declara que toda a paisagem de colinas niveladas da Depressão Periférica Paulista fazia parte de uma superfície aplainada que ele denominou de Superfície Neogênica.

No final dos anos 50, Ab’Sáber e Bernardes (1958) também identificaram um nível de colinas niveladas no Vale do Paraíba, considerando a provável existência de uma antiga superfície embutida ao longo do vale, sendo contínua em alguns pontos, onde é de mais fácil identificação, e dissecada em outros, onde é difícil sua observação. 
Ab'Sáber (1969d) também identifica na região de Campinas colinas niveladas a qual denomina de Superfície de Viracopos, que é nada mais nada menos que um setor localizado da Superfície Neogênica de De Martonne. Em outros setores, identifica a mesma superfície como sendo oriunda de uma fase de pediplanação neogênica, a ela se referindo nos seguintes termos,

\begin{abstract}
"Através de uma revisão recente do assunto, podemos considerar que sejam três os núcleos principais de pediplanação interplanática neogênica no Estado de São Paulo: 1. a depressão periférica paulista... 2. as bordas aplainadas da Bacia de São Paulo, trechos limitados da Bacia de Taubaté, e penetrações descontínuas das aplainações neogênicas nas áreas serranas interpostas entre a bacia de São Paulo e a depressão periférica (sobretudo nos arredores da bacia de Jundiaí) 3. a zona dos baixos chapadões da área central da Bacia do Paraná..." (AB'SÁBER, 1969d, p. 62).
\end{abstract}

Portanto, vê-se que Ab'Sáber faz considerações importantes sobre a ocorrência de prováveis aplainamentos neogênicos por pediplanação. No entanto, as superfícies originadas deste aplainamento somente podem ser evidenciadas em alguns setores, em razão de ter sido praticamente dissecado pelos processos erosivos Quaternários posteriores.

Almeida (1964b) não acredita na existência de uma superfície neogênica oriunda de somente um ciclo erosivo como colocava De Martonne. Embora ele identifique superfícies embutidas como a Superfície do Alto Tietê, considera as mesmas como oriundas de ciclos erosivos locais que podem ter idades diversas, sendo posteriores à Superfície Japi e anterior à sedimentação Pliocênica das "camadas de São Paulo". Este autor considera a possível existência de um aplainamemto neogênico regional, desde que seja possível fazer a correlação deste com o rebaixamento eustático ocorrido por volta do Neomioceno (10,8 Ma) (Ponçano e Almeida, 1993).

Essa sua indagação é fundamentada nas curvas de oscilação do nível eustático de Haq et al (1987) e nas discordâncias erosivas existentes nos sedimentos das bacias de Campos e Santos, pesquisados por Viana et al (1990) e Pereira e Macedo (1990). Todavia, coloca tal situação apenas no campo de uma hipótese, não sendo atualmente possível provar que essas discordâncias sejam "testemunhas" de um aplainamento neogênico regional. Ele também não faz muita menção sobre a natureza desse aplainamento, se por erosão geoquímica ou por etchplanação.

Ponçano e Almeida (1993) ainda recuperam uma significativa proposição de Ab’Sáber (1969e), que destaca a importância de uma provável superfície neogênica, como plano de 
base para um conjunto de evidências que marcam o fim dos acontecimentos relativos a desnudação Terciária e início da história Quaternária no Estado de São Paulo. Se é que existiu mesmo um aplainamento neogênico, este deve servir como importante marco geomorfológico de mudança da evolução geomórfica das terras do Planalto, ou seja, é a partir dele que se deve estabelecer os estudos Quaternários, podendo ser as superfícies embutidas do Planalto, não somente patamares de superfícies deslocados por tectônica moderna, mas evidências de fases posteriores de ciclos erosivos que atingiram o mesmo, devendo aí o problema da tectônica moderna, ser colocado em um outro ângulo de visão. Haveria as duas hipóteses, ou seja, tectônica e aplainamento atuariam juntos e deixariam evidências que podem levar a sérios equívocos de interpretação, com sobreposição das variáveis que estabelecem a investigação destes compartimentos de relevo? Poderia as evidências de uma tectônica moderna fazerem crer na existência de ciclos erosivos e as evidências de relevos oriundos de aplainamento levarem a considerar a predominância de variáveis tectônicas? São perguntas que exigem, de todo modo, respostas complexas e investigações e pesquisas profundas.

A questão das superfícies embutidas tem sido trabalhada também por outros geomorfológos, em pesquisas de cunho mais regional como Modenesi (1974), Penteado (1968) e Coltrinari $(1974,1992,2002)$. Trabalhando na transição do Planalto Atlântico para a Depressão Periférica, na região de Itu-Salto Modenesi (op. cit.) reconhece dois níveis de colinas, esculpidos em rochas cristalinas, que correlaciona à Superfície Neogênica de De Martonne. O mesmo também faz Penteado (op. cit.), em um setor de transição de cuestas para a depressão periférica, onde identifica dois níveis de superfícies neogênicas, dando o nome local para Superfície Urucaia, para a mais antiga e Superfície Rio Claro para a mais nova.

Na região do Vale do Rio Paraíba do Sul, mais especificamente nas proximidades de Guaratinguetá-Aparecida, Coltrinari (1974) fez um trabalho detalhado de cartografia geomorfológica, tendo identificado, em um nível altimétrico de 680-770 metros, um setor descontínuo da Superfície Neogênica, dando o nome local de Superfície de Guaratinguetá. Segundo esta autora, os remanescentes desta superfície podem também ser observados, com maior grau de continuidade, nas proximidades da encosta NW da Serra do QuebraCangalha, onde aparece embutida no vale do Rio Paraíba do Sul. 
Em sua tese de livre docência, Coltrinari (2002) estuda a evolução geomorfológica do Planalto de São José dos Campos, onde trabalha com a hipótese de rebaixamento e aplainamento deste setor do vale do Paraíba do Sul, fundamentado na teoria de Büdel (1982) de aplainamento duplo por processos geoquímicos de dissecação do relevo. Entretanto, em sua abordagem faz uma modificação da aplicação de tal teoria, não confirmando o aplainamento e rebaixamento duplo do relevo por sub-superfície e em superfície, como faz valer esta teoria, mas lançando uma nova ótica, onde o aplainamento e formação desse Planalto de caráter embutido ao longo do vale se daria por processos geoquímicos ocorrentes no desenvolvimento e evolução da cobertura pedológica, na extensão das rochas sedimentares Terciárias. Faz tal abordagem fundamentada em conhecimentos oriundos da linha de trabalho desenvolvida por Filizola e Boulet $(1993,1996)$ e Filizola (1993), dentro da ótica do estudo metodológico da análise estrutural da evolução da cobertura pedológica na sua associação com o relevo.

A principal característica deste trabalho de Coltrinari (2002) é a recuperação da hipótese de De Martonne (1944) sobre a gênese e evolução da Superfície Neogênica por processos químicos de evolução do relevo. Mais do que identificar uma superfície embutida nos vales é feito também uma correlação desta com outras superfícies ocorrentes na depressão periférica paulista, a qual é associada ao aplainamento neogênico derivado por processos geoquímicos de evolução do relevo, Coltrinari (2011).

Desta forma, ocorre aqui um outro ângulo de abordagem a qual os "neotectonistas" não fazem nenhuma menção, o da formação e evolução dos Planaltos por processos geoquímicos fundamentados na dinâmica da cobertura pedológica. Assim, aparecem novas perguntas. Haveria algum processo genético de ordem geoquímica nos planaltos embutidos e superfícies cimeiras que seria responsável pela formação dos mesmos? Qual seria a participação das variáveis geoquímicas na formação de tais compartimentos, seja os embutidos, sejam os de cimeira? Quais seriam o papel e a importância das taxas de denudação?

Em um estudo analisando a evolução do relevo da bacia de Taubaté por processos geoquímicos em rochas sedimentares Terciárias, Filizola e Boulet $(1993,1996)$ calcularam uma taxa de rebaixamento por desnudação geoquímica da ordem de 0,23 $\mathrm{mm}$ por ano ou 23 m a cada 100 mil anos para as colinas niveladas deste setor do vale do Paraíba. O estudo também foi fundamentado na análise estrutural da cobertura pedológica e teve como 
objetivo principal investigar a gênese de depressões fechadas que ocorrem nas rochas quartzo-cauliníticas da região.

A principal conclusão foi a de que a erosão química é o principal agente atuante na formação do relevo regional. Entretanto, se tomarmos o Paleógeno como o marco inicial de origem do soerguimento das terras do Planalto como propõe Almeida e Ponçano (1998) e, tendo o Paleógeno, iniciado a aproximadamente 80 milhões (AP), teríamos, de acordo com os cálculos de Filizola e Boulet (op. cit.), dissecado 800 metros de relevo neste setor de colinas que possuem atualmente 700 metros em média de altitude. Entretanto, estudos com traços de fissão em apatitas realizados por Vignol-Lelarge et al (1994) no Arco de Ponta Grossa e Gallagher et al (1994) na Serra do Mar Paranaense, bem como outros trabalhos da literatura, vêm confirmando processos de soerguimento do Planalto que fizeram atingir algo entre 3.500 a 4.000 metros de altitude em média. Na linha de raciocínio da erosão geoquímica, subtraindo 800 metros dos 4.000 metros que teria o Planalto nos pontos mais altos, teríamos que ter hoje compartimentos que atingissem 3.200 metros de altitude. Todavia, pelo que se sabe o Planalto Atlântico não atinge tal cota em nenhum setor, sendo o ponto mais alto em torno de 2.200 metros no Itatiaia.

Fica desta forma, evidenciada uma questão que não se relaciona, que não permite uma correlação, apresentando forte contradição. Neste sentido, é possível a existência de fases de maior dissecação química do relevo que é praticamente impossível de identificar na escala do tempo geológico, tal a quantidade de variáveis que podem intervir nos cálculos e na tentativa de entendimento dos processos de desnudação.

Portanto, há questões sérias a serem elucidadas na investigação da origem das terras altas do Planalto que envolve não somente variáveis tectônicas e de análise geoquímica, mas de fases de maior rebaixamento do relevo associado as fases de estabilidade tectônica dos compartimentos. A análise geoquímica coloca novas complicações na interpretação da origem das terras altas no campo das variáveis tectônicas, da abordagem morfoclimática e em função da sua própria análise, uma vez que, fica difícil acreditar em rebaixamento do relevo, através de uma taxa de dinâmica uniforme sem grandes rupturas dos processos na escala do tempo geológico.

Há também, e deve-se frisar tal fato, certa continuidade da Superfície Neogênica em outros setores do Planalto que coloca em dúvida, a hipótese de que o tectonismo teria formado, a partir de uma só superfície - por efeito de fragmentação e desmantelamento - às outras 
superfícies que ocorrem embutidas em certos setores. A continuidade do processo de aplainamento neogênico é evidenciado pela presença de superfícies que estão na mesma posição geomorfológica das que são encontradas no vale do Paraíba do Sul e depressão periférica, portanto, em pontos muito distantes. Tal fato é muito bem notificado por Ponçano e Almeida (1993) e Ab'Sáber (2001), mas deixado de lado por autores da linhagem tectônica, sendo omitidas por uns e negligenciadas por outros.

\section{CONSIDERAÇÕES FINAIS}

Diante do exposto pelas correntes que podem ser divididos os trabalhos que estudaram os relevos do Planalto Atlântico, se percebe que nenhuma delas é capaz de explicar totalmente as origens das terras altas. Todas apresentam problemas quando confrontadas entre si, por meio de modelos teóricos de explicação do relevo onde há o predomínio de uma variável sobre outras, colocando sérios problemas quanto às informações coletadas no âmbito da interpretação tectônica e geomórfica. Permanecem incógnitas antigas e surgem outras. A mais complexa é a corrente que trata das superfícies embutidas e dos processos geoquímicos colocando novas complicações na interpretação da origem das terras altas no campo das variáveis tectônicas, da abordagem morfoclimática e em função da sua própria análise.

Em todas as correntes que procuram estabelecer melhor os processos morfogenéticos e morfodinâmicos da evolução do Planalto, há problemas novos que aparecem e/ou paradigmas velhos que precisam ser revisados à luz das técnicas modernas de pesquisa, na área da geomorfologia estrutural e dinâmica. Tanto uma corrente como outra, procura, a seu tempo e na melhor das hipóteses, avançar na elucidação dos problemas e indagações deixados por trabalhos de uma corrente anterior. No entanto, os problemas antigos ainda persistem, convivendo lado a lado com as novas indagações.

\section{REFERÊNCIAS BIBLIOGRÁFICAS}

AB'SÁBER, A. N. Conhecimentos sobre as flutuações climáticas do Quaternário no Brasil. Bol. Soc. Bras. Geol., 6:839-849, 1957. 
O relevo brasileiro e seus problemas. In: Brasil, a terra e o homem: As bases

físicas. Org. por Aroldo de Azevedo. São Paulo, Ed. Nacional, v.1: 135-250, 1964.

AB'SÁBER, A. N. O Quaternário na Bacia de Taubaté: estado atual dos conhecimentos.

Geomorfologia 7, USP - IG. São Paulo, 1969a.

- O Quaternário na Bacia de São Paulo: estado atual dos conhecimentos.

Geomorfologia, 8, USP-IG. São Paulo, 1969b.

. Pedimentos e bacias detríticas pleistocênicas em São Paulo. Geomorfologia, 9.

USP-IG. São Paulo, 1969c.

. Uma revisão do Quaternário Paulista: do presente para o passado. Revista

Brasileira de Geografia, ano 31, n 04, outubro-dezembro de 1969, pp. 1 - 33. Rio de Janeiro, 1969d.

O Quaternário no Estado de São Paulo: do presente para o passado. Tese de cátedra, FFLCH - USP, $1969 \mathrm{e}$.

. Páleo-clima e Páleo-ecologia. In: "Temas de Arqueologia Brasileira". 1. PaleoÍndio. Schimitz, Barbosa e Ribeiro (Eds.). Anuário de Divulgação Científica, Goiânia, GO, n. 5, p. 33-51, 1978-1980.

- Paleo-climas e migrações pré-históricas na América do Sul. Revista de PréHistória, São Paulo, v. 6, p. 127-128, 1984.

Páleo-climas quaternários e pré-história da América Tropical. Dédalo: Revista de Arqueologia e Etnologia, São Paulo, n. 1, p. 9-25, 1989.

As bases do conhecimento sobre os paleoclimas modernos da Amazônia. Ciência Hoje, SBPC, v. 16, n. 93, p. 1-3, 1993.

- Megageomorfologia do Território Brasileiro. IN: Geomorfologia do Brasil. Org. S.B. da CUNHA e A.J.T. GUERRA, Editora Bertrand Brasil, Rio de Janeiro, 2001, p. 71-106. 
AB'SÁBER, A. N e BERNARDES, N.; Vale do Paraíba, Serra da Mantiqueira e arredores de São Paulo. XVIII Congresso Internacional de Geografia, Guia de Excursão n 04, C.N.G., Rio de Janeiro, 1958.

ALMEIDA. F. F M. de.; Os Fundamentos Geológicos. In: Brasil, a terra e o homem. (org. por Aroldo de Azevedo). São Paulo, 1964a. v. 1, 55-133.

. Fundamentos geológicos do relevo paulista. São Paulo, Instituto de Geografia, boletim 41 p. 167-263, 1964b.

. Diferenciação tectônica da Plataforma Brasileira. In: SBG, Congr. Bras. Geol., 23, Salvador, Anais. Salvador, 1969. p. 29-46.

. The System of Continental Rifts Bordering the Santos Basin, Brasil. Anais Acad. brasil. Ciênc., 48 (supl.): 15-26, 1976.

ALMEIDA, F. F. M. de et. al.; Magmatismo pós-Paleozóico no Nordeste oriental do Brasil. Rev. Bras. Geoc., 18:451-462, 1988.

ALMEIDA, F.F.M. de; CARNEIRO, C.D.R.; Origem e evolução da Serra do Mar. Revista Brasileira de Geociências, São Paulo, 1998. v. 28, n. 2, p. 135-150, jun.

ASMUS, H. E. (et al).; Integração geológica regional da Bacia do Espírito Santo. In: Congresso Brasileiro de Geologia, 25, São Paulo, 1971. Anais. V.02, p. 235-252.

ASMUS, H. E.; Controle estrutural da deposição mesozóica nas bacias da margem continental brasileira. Rev. Bras. Geoc. V. 05, p. 160-175, 1975.

ASMUS, H. E., FERRARI. A. L.; Hipótese sobre a causa do tectonismo cenozóico na região sudeste do Brasil. In: PETROBRAS. Aspectos estruturais da margem continental leste e sudeste do Brasil. Rio de Janeiro, 1978: PETROBRAS/CENPES/DINTEP. p. 75-88. (Série Projeto REMAC 04).

AZEVEDO, Jr. M. F.; Integração entre o preenchimento sedimentar cenozóico das bacias de Campos e Santos e a evoluçao tectônica e geomorfológica das áreas continentais adjacentes. Ouro Preto, 1991. EM-UFOP, Dissert. Mestr., 160 p. 
BIGARELLA, J. J. (org.).; Estrutura e origem das paisagens tropicais e subtropicais. Vol. 01 e vol. 02, 2a ed. Florianópolis: Ed. da UFSC, 2007a/b.

BIGARELLA, J. J. (org.).; Estrutura e origem das paisagens tropicais e subtropicais. Vol. 03, Florianópolis: Ed. da UFSC, 2003.

BIGARELLA, J. J. e AB'SABER, A. N.; Quadro provisório dos fatos sedimentológicos, morfoclimáticos e paleoclimáticos na Serra do Mar paranaense e catarinense. Boletim Paranaense de Geografia, n²/5, p. 91, Curitiba, 1961.

BIGARELLA, J. J. e ANDRADE, G. O. de.; Contribution to the study of the Brazilian Quaternary, Sp. Pap. 84, pp. 433-451. Geol. Soc. Of America, 1965.

BIGARELLA, J. J. ANDRADE LIMA, e D. RIEHS, P.J.; Considerações a respeito das mudanças paleoambientais na distribuição de algumas espécies vegetais e animais no Brasil. Anais da Acad. Bras. de Ciências. Rio de Janeiro, 1975. 47 (supl.):411-464.

BIGARELLA, J. J. MARQUES, F. P. L. AB'SÁBER, A. N.; Ocorrência de pedimentos remanescentes nas fraldas da serra do Iquererim (Garuva, SC). Bol. Par. Geog. , Curitiba, 1961. 4/5:82-93.

BIGARELLA, J. J. e MOUSINHO, M.R.; Considerações a respeito dos terraços fluviais, rampas de colúvio e várzeas. Curitiba, Bol. Paran. Geogr., 16 e 17:153-197, 1965.

BIGARELLA, J. J. e MOUSINHO, M.R. e SILVA, J. X.; Considerações a respeito da evolução das vertentes. Curitiba, Bol. Paran. Geogr. 16 e 17:89-116, 1965a.

BIGARELLA, J. J.: MOUSINHO, M. R. e SILVA, J. X.; Pediplanos, pedimentos e seus depósitos correlativos no Brasil. Curitiba, Bol. Paran. Geogr. 16 e 17:117-151, 1965.

BISTRICH, C. A.; Análise estratigráfica e geomorfológica do Cenozóico da região de AtibaiaBragança Paulista, Estado de São Paulo. Rio Claro, 2001. IGCE-UNESP, Tese Dout., 184 p.

BÜDEL, J. Climate Geomorphology. Princeton University Press (trad. L. Fischer \& D. Busche), 1982. 
COLTRINARI, L.; Contribuição à geomorfologia da região de Guaratinguetá-Aparecida. Tese de doutorado, Departamento de Geografia, USP, 156 p, 1974.

- Geomorfologia e dinâmica quaternária no sudeste do Brasil. Revista do Departamento de Geografia, FFLCH - USP, 6, São Paulo, 1992.

. Evolução Geomorfológica do Planalto de São José dos Campos (SP). Tese de Livre

Docência, Departamento de Geografia, USP, São Paulo, 2002.

. Paleosurfaces in Southeastern Brazil: São José dos Campos Plateau Landform

Evolution. São Paulo, UNESP, Geociências, v. 30, n. 1, p. 113-120, 2011.

DE MARTONNE, E.; Problemas morfológicos do Brasil Tropical Atlântico. Rev. Bras. de Geografia, IBGE - CNG. Rio de Janeiro, 1943-1944. 5(4): 523-550; 6(2): 155-178.

ERHART, H.;. La théorie bio-résistasique et les problèmes biogéographiques et paléobiologiques. C.r. de la Soc. Biogéogr., 1956, pp. 45-63. Paris. (Trad. In Notícia Geomorfológica, n²11, 1966).

ESTRELLA, G. O.; O estágio rift nas bacias marginais do leste brasileiro. In: Congresso Brasileiro de Geologia, 26, Belém, 1972. Anais. V. 03, p. 29-34.

FERRARI, A. L.; Evolução tectônica do Gráben da Guanabara. São Paulo, IGc-USP, Tese doutoramento, 412 p, 2001.

FILIZOLA, H.F.; O papel da erosão geoquímica na evolução do modelado da bacia de Taubaté - SP. Doutorado em Geografia Física, Departamento de Geografia, FFLCH - USP, 1993.

FILIZOLA, H. F. e BOULET, R.; Une évaluation de la vitesse de l'érosion géochimique à partir de l'étude de dépresions fermées sur roches sédimentaires quartzo-kaoliques au Brésil. C.R. Acad. Sci. Paris, 1993. 316, sér.II: 693-700.

Evolution and opening of closed depressions developed in a quartz-Kaolinitic sedimentary substratum at Taubaté basin (São Paulo, Brazil), and analogy to the slope evolution. Geomorphology 16, 1996. 77-86. 
FREITAS, R. O. de.; Relevos policíclicos na tectônica do Escudo Brasileiro. Bol. Paul. Geogr. 7:3-19, 1951a.

. Ensaio sobre o relevo tectônico do Brasil. Rev.Bras.Geogr. Rio de Janeiro, 1951b. XIII(2):171-222.

GALLAGHER, K.; HAWKESWORTH, C.J.; MANTOVANI, M.S.M.; The denudation history of the onshore continental margin of SE Brazil inferred from apatite fission track data. Journal of Geophysical Research, vol. 99, NO. B9, september 10, p. 117-18,145, 1994.

GONTIJO. A. H. F.; Morfotectônica do Médio Vale do Rio Paraíba do Sul: região da Serra da Bocaina, Estados de São Paulo e Rio de Janeiro. Tese de Doutorado, Instituto de Geociências e Ciências Exatas, UNESP - Rio Claro, 1999. 259 p.

HAQ, B. U., et. al.; Mesozoic-Cenozoic cycle chart. Version 3. 1A. s.1.,s.c.p, 1987.

HASUY, Y.; Neotectônica e tectônica ressurgente no Brasil. In: Workshop Neotectônica e Sedimentação Continental Cenozóica do SE do Brasil, 1, Belo Horizonte, 1990. Anais, SBG/MG. Boletim 11, p. 1-32.

HASUY, Y.; PONÇANO, W. L.; Organização estrutural e evolução da bacia de Taubaté. In: Congresso Brasileiro de Geologia, 30, Recife, 1978. Anais, v. 01, p. 368-381.

HIRUMA, S. T.; Significado Morfotectônico dos Planaltos Isolados da Bocaina. Tese de doutoramento. Inst. Geoc. USP, São Paulo, 2007. 212 p.

INSTITUTO DE PESQUISAS TECNOLOGICAS DO ESTADO DE SÃO PAULO - IPT.; Estudos geológicos-tectônicos na Bacia de Resende (RJ) e sedimentos terciários da área de Volta Redonda (RJ) e Bacia de Taubaté (área de Cruzeiro). São Paulo, 1983.: IPT, 2 v. (IPT, Relatório 17 737).

KING, L. C.; A geomorfologia do Brasil oriental. Rev. Brasileira de Geografia, Rio de Janeiro, 1956. XVIII (2): 147-265.

MANCINI, F.; Estratigrafia e aspectos da tectônica deformadora da Formação Pindamonhagaba, Bacia de Taubaté, SP. São Paulo, 1995. IGc-USP, dissert. Mestr. 107 p. 
MEIS, M.R.M.; As unidades morfoestratigráficas neoquaternárias no médio vale do Rio Doce. Anais da Academia Brasileira de Ciências. Rio de Janeiro, 1977. 49: 443-459.

MEIS, M.R.M. e MOURA, J.R.S.; Upper Quaternary sedimentation and hillslope evolution: Southeastern Brazilian Plateau. American Journal of Science, v. 248, p. 132 - 151, 1984.

MODENESI, M. C.; Contribuição à geomorfologia da região de Itu-Salto. São Paulo, Instituto de Geografia, 99p, 1974. (IGEOG. USP. Teses e Monografias, 10).

MELO, M. S. (et. al.).; Geologia e evolução do sistema de bacias tafrogênicas continentais do sudeste do Brasil. Rev. Bras. Geoc., v. 15, n. 03, p. 193-201, 1985.

MELO, M.S.; PONÇANO, W.L.; MOOK, W. G.; AZEVEDO, A.E.G.; Datações C14 em sedimentos quaternários da Grande São Paulo. In: Congresso da ABEQUA, 1, Porto Alegre, 1987. Anais...p.427-436.

MELLO, C. L.; Fácies Sedimentares, Arquitetura Deposicional e Relações Morfoestratigráficas em um Sistema de Leques Aluviais Holocênicos: Aloformação Manso - Médio Vale do Rio Paraíba do Sul (SP/RJ). Inst. de Geociências, Universidade Federal do Rio de Janeiro, Rio de Janeiro, Dissertação de Mestrado, 188p, 1992.

MOHRIAK, W. U. Recursos energéticos associados à ativação tectônica Mesozóico-Cenozóica da América do Sul. In: Geologia do Continente Sul-Americano: Evolução da Obra de Fernando Flávio Marques. Org. MANTESSO-NETO, V. (et. al.). Editora Beca, São Paulo, p. 293319.

MOURA, J.R.S.; Transformações Ambientais Durante o Quaternário Tardio no Médio Vale do Rio Paraíba do Sul (SP-RJ). Rio de Janeiro, 1990. 267 p. (Tese de doutorado, Depto. Geologia - IGEO/UFRJ).

MOURA, J.R.S.; PEIXOTO, M.N.O.; SILVA, T.M. e MELLO, C.L.; Mapas de feições geomorfológicas e coberturas sedimentares quaternárias: abordagem para o planejamento ambiental em compartimentos de colinas no Planalto Sudeste do Brasil. In: Congresso Brasileiro de Geologia, 37, São Paulo (SP), 1992. Boletim de Resumos Expandidos, SBG-SP, v.1, p. 60-62. 
MOURA, J. R. S. e MELLO, C. L.; Classificação aloestratigráfica do Quaternário superior na região de Bananal (SP/RJ). Revista Brasileira de Geociências, São Paulo, 1991. v. 21, n.3, p. 236-254

MOURA, J. R. da S. e SILVA, T. M. Complexos de Rampas de Colúvio. IN: Geomorfologia do Brasil. Org. S.B. da CUNHA e A.J.T. GUERRA, Editora Bertrand Brasil, Rio de Janeiro, 2001, p. 143-180.

PONÇANO, W.L; ALMEIDA, F. F. M. de.; Superfícies erosivas nos planaltos cristalinos do leste paulista e adjacências: uma revisão. Cadernos IG/Unicamp, 3 (1): 55-90, 1993.

PENTEADO, M. M.; Geomorfologia do setor centro-ocidental da depressão periférica paulista. Tese doutoramento, Rio Claro, 1968: FFCL, 160p.

PEREIRA, M. J., MACEDO, J. M.; A Bacia de Santos: perspectivas de uma nova província petrolífera na plataforma continental sudeste brasileira. Bol. Geoc. Petrobrás, Rio de Janeiro, 1990. v. 04, n. 01, p. 3-11.

REGO, L. F. de M.; As formações cenozóicas de São Paulo. Anais da Escola Politécnica de São Paulo, p. 231-267, São Paulo, 1933.

RICCOMINI, C.; O Rift continental do Sudeste do Brasil. São Paulo, Igc - USP, tese doutorado, 256p, 1989.

RICCOMINI, C. (et. al.). Evolução Geológica Continental do Sudeste do Brasil. In: Geologia do Continente Sul-Americano: Evolução da Obra de Fernando Flávio Marques. Org. MANTESSONETO, V. (et. al.). Editora Beca, São Paulo, 2004. p. 383-405.

$\mathrm{RICH}$, J. L.; Problems in Brazilian geology and geomorphology suggested by reconnaissance in summer of 1951. Fac. Filos. Ciên. Letras, Univ. São Paulo, 1953. Bol. 146, 79 p. (Geologia 9).

ROSS, J. L. S - O Registro Cartográfico dos Fatos Geomorfológicos e a Questão da Taxonomia do Relevo. Revista do Departamento de Geografia, 6, FFLCH-USP, São Paulo, 1992.

O Relevo Brasileiro, as Superfícies de aplainamento e os Níveis Morfológicos. Revista do Departamento de Geografia, 5, FFLCH- USP, São Paulo, 1991. 
RUELLAN, F.; Evolução geomorfológica da baía de Guanabara e das regiões vizinhas. Revista Brasileira de Geografia, 6: 445-508, 1944.

Excursão ao vale do Rio Paraíba e à Serra da Mantiqueira. Anais da $1^{\circ}$ Reunião

Pan-Americana de Consulta sobre a Geografia, vol. II p. 209-245, Rio de Janeiro, 1952.

SAADI, A. Neotectônica da Plataforma Brasileira: esboço e interpretações preliminares. Geonomos, Belo Horizonte, 1993, v 1, n. 1, p. 1-15.

SALVADOR, E. D. e RICCOMINI, C.; Neotectônica da região do Alto Estrutural de Queluz, SPRJ, Brasil. Rev. Bras. Geoc., 25: p. 151-164, 1995.

SCHOBBENHAUS, C. (et.al.).; Geologia do Brasil: Texto explicativo do mapa geológico do Brasil e da área oceânica adjacente, incluindo depósitos minerais, escala 1: 2.500.000. Brasília, MME-DNPM, 501p, 1984.

VIANA, A. R. KOWSMANN, R.O., CASTRO, D. D. de.; A discordância do Mioceno Médio / Superior: um marco regional no talude da Bacia de Campos. In: Congresso Brasileiro de Geologia, 36, 1990, Natal, 1990. Anais... v.01, p. 313-323.

VIGNOL-LELARGE, M. L. M. ; SOLIANI JR.E.; POUPEAU, G.; Datação pelos traços de fissão do domínio meridional da Serra do Mar (Arco de Ponta Grossa - Brasil). Congresso Brasileiro de Geologia, 38, Camboriú, 1994. Boletim de Resumos Expandidos, SBG. V.2, 1994, p. 379-380.

VERVLOET, R. J. H. M.; Condicionantes morfológicos e estruturais na dinâmica fluvial da bacia hidrográfica do Rio Benevente - Espírito Santo. Dissertação de Mestrado, Programa de Pos-Graduação em Geografia Física, FFLCH - USP, 415 p. São Paulo, 2009.

ZALÁN, P. V; OLIVEIRA, J. A. B. de.; Origem e evolução estrutural do Sistema de Riftes Cenozóicos do Sudeste do Brasil. B. Geoci. Petrobras, v. 13, n.2, p. 269-300, maio/Nov, 2005.

Artigo recebido em 24/12/2011.

Artigo aceito em 15/02/2012. 